\title{
A CASE OF GALL STONE ILEUS
}

Husain M. Gheewala1, Surajsinh A. Chauhan², Akhil Palod³, Dharmesh J. Balsarkar, Rahul V. Kandekar5

\section{HOW TO CITE THIS ARTICLE:}

Husain M. Gheewala, Surajsinh A. Chauhan, Akhil Palod, Dharmesh J. Balsarkar, Rahul V. Kandekar."A case of Gall Stone Ileus". Journal of Evolution of Medical and Dental Sciences 2015; Vol. 4, Issue 55, July 09;

Page: 9670-9673, DOI:10.14260/jemds/2015/1395

ABSTRACT: Gall stone ileus causing intestinal obstruction is seen in 1-4\% of cases.[1] We present a case of 66 years female presenting to us with features of acute intestinal obstruction. Investigations showed the features of cholecystoduodenal fistula with intestinal obstruction secondary to large gallstone in the ileum. We discussed here the presentation and management of patient with gallstone ileus.

KEYWORDS: Gallstone ileus, Intestinal obstruction, Treatment/Management.

CASE PRESENTATION: A 66 year female known case of diabetes mellitus, ischaemic heart disease, with hypothyroidism and medical renal disease presented with generalised pain in abdomen, vomiting and not passing flatus and stool since 3 days. On examination there was generalised abdominal distension along with tenderness and guarding.

Abdominal X-ray showed features suggestive of acute intestinal obstruction (Fig. 1).

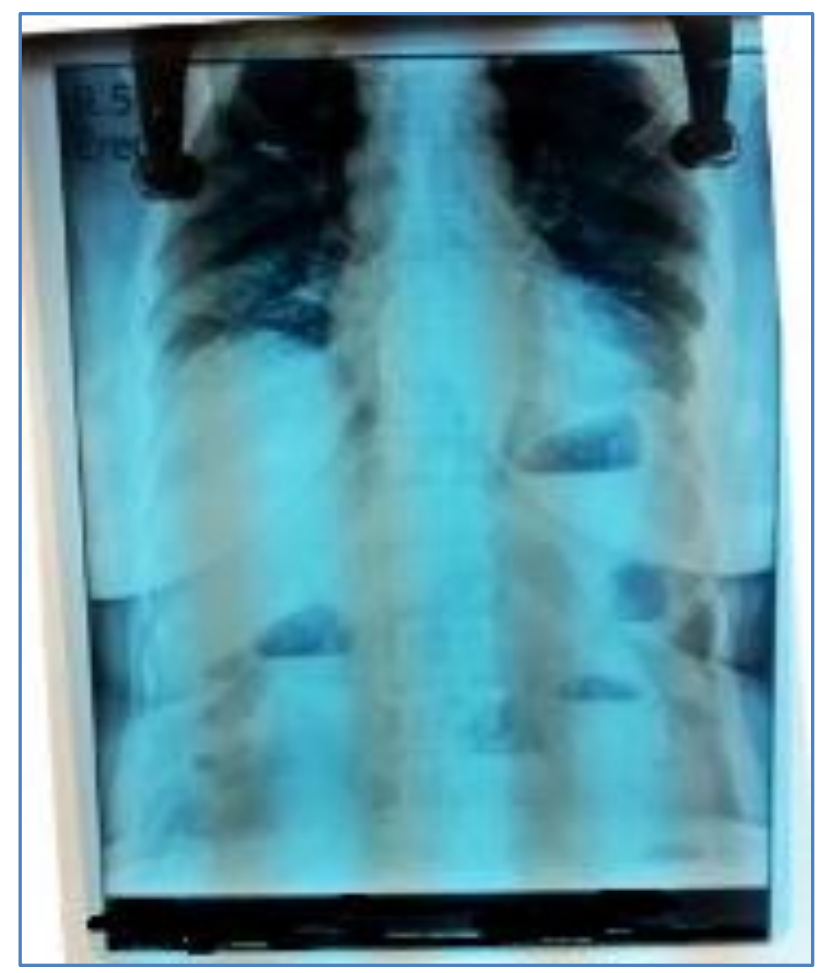

Fig. 1

CT abdomen showed features of chronic cholecystitis, cholecysto duodenal fistula with gall stone ileus due to large impacted stone in terminal ileum. (Fig 2A, 2B). 


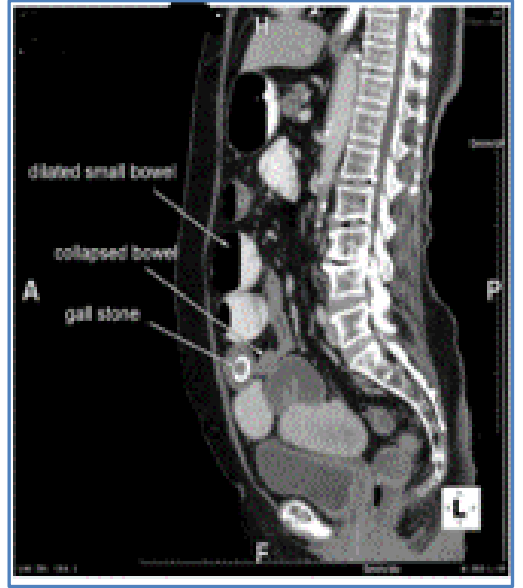

Fig. 2A

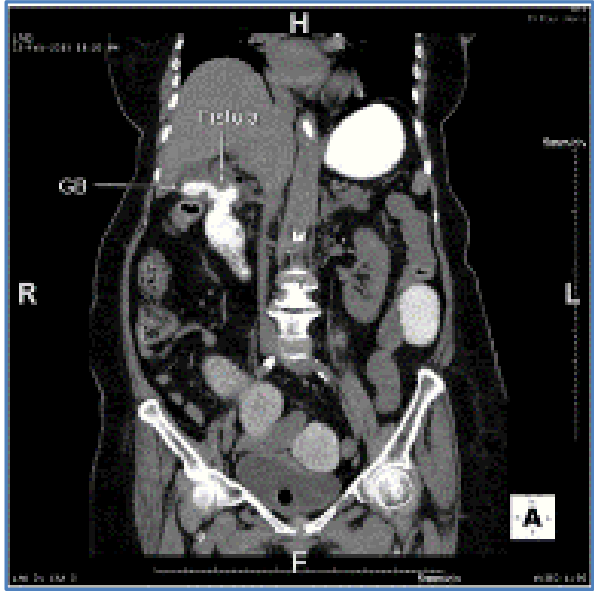

Fig. 2B

In view of above investigations suggestive of gall stone ileus with acute intestinal obstruction decision to perform an exploratory laparotomy to relieve the obstruction was taken.

At surgery a $3 \mathrm{~cm}$ impacted stone was found $20 \mathrm{~cm}$ proximal to ileocaecal junction with dilatation of proximal small bowel loop and collapsed distal bowel loops [Fig. 3]. Since the gallstone could not be dislodged it was removed by performing an enterotomy, which was then closed in 2 layers. Cholecystectomy with closure of cholecystoduodenal fistula was deferred as the patient had dense adhesions in the supracolic compartment. Patient had an uneventful recovery.

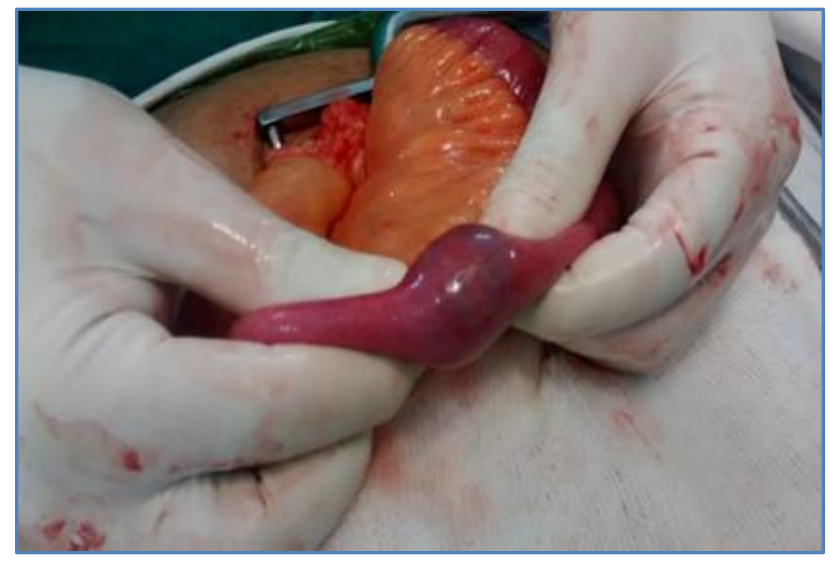

Fig. 3

DISSCUSSION: Gallstone ileus is 3 to 5 times more frequently seen in women than men [2].The mortality ranges from 12-18\%.[3] The gallstone enters the intestines through a fistula formed between the gallbladder and the duodenum, stomach or colon. Cholecystodudenal fistula is commonest cause of fistula seen in $68 \%$ of cases.[4] The terminal ileum is the most frequent site of obstruction [1] followed by duodenal obstruction. ${ }^{[2]}$ Other impaction sites include jejunum (30\%) followed by in colon (2.5\%) cases. The classical radiologic triad or Riglers triad of pneumobilia, small bowel obstruction and ectopic gallstone is specific for this disease, is seen only in 9-14\%.[5] Plain 
abdominal radiographs may reveal signs of small bowel obstruction and concomitant aerobilia to suggest the diagnosis.[5,6] Computed tomography is the investigation of choice[7] as was seen in the reported case. The principal goal in management of gallstone ileus is a quick effective relief of mechanical bowel obstruction.[7] For stone in within reach of an endoscope, either in the proximal small bowel or in the colon, can be treated by lithotripsy and removal of the fragment.[2]

Extracorporeal shockwave lithotripsy has also been used successfully, but this method is limited by bowel gas.[7] Surgical treatment can be one stage or two stage approach. In stable patients without any comorbidities, entorotomy with stone removal to relieve obstruction can be combined with cholecystectomy along with closure of fistula. ${ }^{[8]}$ If the patient is having high risk factors then a two stage approach is preferred, enterotomy with stone extraction to relieve obstruction and followed by cholecystectomy and repair of fistula at a later date. In severely morbid patients just an enterolithotomy is performed, cholecystectomy is not done unless the patient complains of recurrent symptoms. ${ }^{[9]}$ With advances in laproscopy, laparoscopic management of gallstone ileus and the associated cholecystoduodenal fistula is also feasible and safe.[10]

CONCLUSION: Gall stone ileus although rare cause of small bowel obstruction, should be included in the algorithm of diagnosis in select group of patients with history of gall stone as a cause of intestinal obstruction.

\section{REFERENCES:}

1. Chatterjee S, Tamonas C, Goutan G, Ambar G: Gallstone ileus an atypical presentation and unusual location. Int J Surj 2008, 6(6): e55-e56.

2. Chen-Wang C, Shou-Chuan S, Shee-Chau L, Cheng-Hsin C: Gallstone ileus: a disease easily ignored in the elderly. Int J Gastenterology 2008, 2(1):18-21.

3. Deepak J, Ali V, Tom MR, Fox C, Arun D: Bouveret's syndrome as an unusual cause of gastric outlet obstruction: a case report. Journal of Medical Case Reports 2007, 1: 73.

4. Williams JB, Mehta S G, Vu T, Wonderlich DA: Gallstone ileus. The journal of emergency medicine. Doi: 10.1016/J.Jemer.11.063.

5. Elabsi M, Amraoui M, Errougani A, Chkof MR. Diagnosis and treatment: gallstone. Digestive and liver disease 2007, 39: 180-181.

6. Strauss M, Jacqunod P, Sezeur A, Houdart R, Ziza JM: Un syndrome occlusive. La revue de medicine interne 2009, 30(1): 69-70.

7. Fatima E.Z, El Bachir B, Abdelmalek O, Khalid M and Khalid A.T. Uncommon cause of small bowel obstruction - gallstone ileus: a case report. Cases Journal 2009, 2: 9321.

8. Sapula, R. And Skibinski, W. Gallstone ileus as a complication of cholecystolithiasis. SurgEndosc. 2002; 16: 360.

9. Rodriguez-Sanjuan, J.C., Casado, F., Fernandez, M.J., Morales, D.J., and Naranjo, A. Cholecystectomy and fistula closure versus enterolithotomy alone in gallstone ileus. Br J Surg. 1997; 84: 634-637.

10. El-Dhuwaib, Y. and Ammori, B.J. Staged and complete laparoscopic management of cholelithiasis in a patient with gallstone ileus and bile duct calculi. Surg Endosc. 2003; 17: 988989. 


\section{CASE REPORT}

\section{AUTHORS:}

1. Husain M. Gheewala

2. Surajsinh A. Chauhan

3. Akhil Palod

4. Dharmesh J. Balsarkar

5. Rahul V. Kandekar

\section{PARTICULARS OF CONTRIBUTORS:}

1. Senior Registrar, Department of Surgery, Topiwala National Medical College \& BYL Nair Hospital, Mumbai.

2. $3^{\text {rd }}$ Year Resident, Department of Surgery, Topiwala National Medical College \& BYL Nair Hospital, Mumbai.

3. $3^{\text {rd }}$ Year Resident, Department of Surgery, Topiwala National Medical College \& BYL Nair Hospital, Mumbai.

FINANCIAL OR OTHER

COMPETING INTERESTS: None
4. Additional Professor, Department of Surgery, Topiwala National Medical College \& BYL Nair Hospital, Mumbai.

5. $2^{\text {nd }}$ Year Resident, Department of Surgery, Topiwala National Medical College \& BYL Nair Hospital, Mumbai.

\section{NAME ADDRESS EMAIL ID OF THE} CORRESPONDING AUTHOR:

Dr. Husain M. Gheewala, Veena Beena Apartment, I-wing, Flat No. 303, $3^{\text {rd }}$ Floor,

A. D. Marg, Sewree (W), Mumbai-400015.

E-mail: gheewalahusian@gmail.com

Date of Submission: 28/06/2015.

Date of Peer Review: 29/06/2015.

Date of Acceptance: 03/07/2015.

Date of Publishing: 08/07/2015. 